\title{
Design and Optimization on Natural Lighting of One Large Shopping Mall in Guangzhou
}

\author{
Huang Yu Heng ${ }^{1, a}$ \\ ${ }^{1}$ Institute of huazhong university of science and technology building gauge level 2013 master \\ of architecture, Wuhan, Hubei, 430074, China \\ araymondhuang91@126.com
}

Keywords: Guangzhou; large shopping mall; natural lighting; design optimization

\begin{abstract}
DEST and Radiance software to make simulation research on energy consumption of one large shopping mall in Guangzhou, it makes research on expression of indoor light environment and energy consumption of building under design strategy of different natural lighting by changing the shading way and skylight area of building on computer simulation.
\end{abstract}

\section{Modeling parameter setting}

The skylight of this building adopts Low-E window of hollow double silver(CED13-40S/TS film), the thickness is $6+12+6(\mathrm{~mm})$ and heat transfer coefficient $\mathrm{K}$ is $1.63 \mathrm{~W} / \mathrm{m}^{2} \cdot \mathrm{K}$, shading coefficient SC is 0.27 .

According to the above parameters, the modeling in DEST and Radiance is as follows:

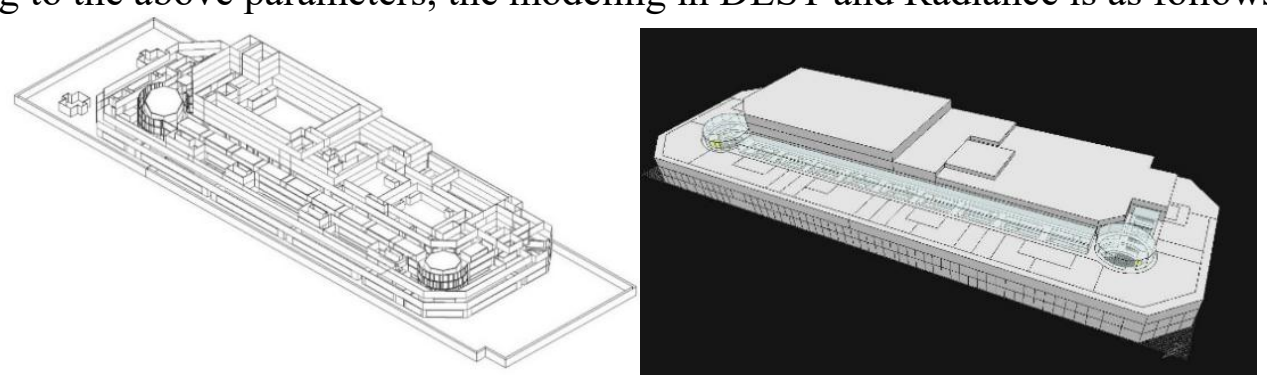

Figure 1 Building model diagram in DEST and Radiance

\section{Demonstration on simulation accuracy of Radiance}

In order to demonstrate the accuracy of Radiance lighting simulation software, we went to project site to make actual measurement on June of 2015 and recorded indoor illumination distribution under 2 kinds of working conditions on the first floor: sunny day and cloudy day in this project, this distribution is used to demonstrate accuracy of Radiance simulation.

This building only opens some lights under condition that there is natural light in daytime, during 2 days of actual measurement, the indoor lighting of building is mainly natural lighting in daytime and artificial lighting in nighttime, the lights basically keeps completely opening.

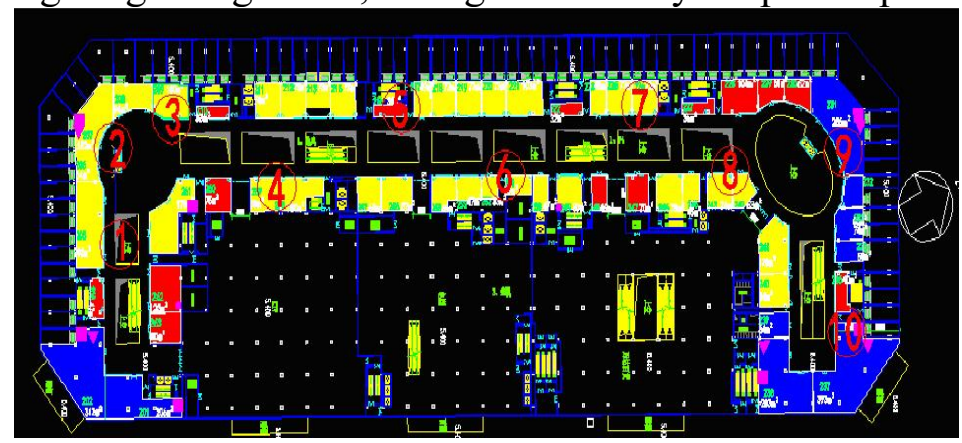

Figure 2 Schematic diagram of illumination test point

The outdoor illumination in sunny day on test is $80001 \mathrm{x}$ or so and $20001 \mathrm{x}$ or so in cloudy day. 
Take pedestrian area on the first floor as object and set simulation time as middy 12 of $15^{\text {th }}$ in June, it sets the same time with the test time. This paper respectively adopts CIE sunny day model and CIE cloudy day model to make simulation on $1200 \mathrm{~mm}$ working plain (it keeps the same plain height on actual measurement) in sunny day and cloudy day, the comparison is as follows compared with actual measurement:

From the diagram we can see that the sunny day working condition simulated by Radiance using CIE sunny day model basically keeps the same with actual measurement result in sunny day, there is only some simulation data in some areas higher than actual measurement value, but the cloudy working condition simulated by using CIE cloudy model has big difference from the actual measurement result in cloudy day. By analyzing its causes, this is may be cloudy weather on actual measurement tends to be cloudy, the penetrated natural light has irregular distribution due to effect of cloud layer in the sky, so it has certain difference from the weather conditions in the cloudy day.

Under the working condition of sunny day during actual measurement, sunlight is hardly shaded by cloud layer, so the rule of indoor illumination change is relatively close to the ideal sky state in June. At 12 of $15^{\text {th }}$ in June, the illumination change calculated by Radiance using CIE sunny model and CIE cloudy model keeps the same, it can judged that its simulation result is relatively correct.

The simulation result under sunny day working condition is indicated by the following diagram:
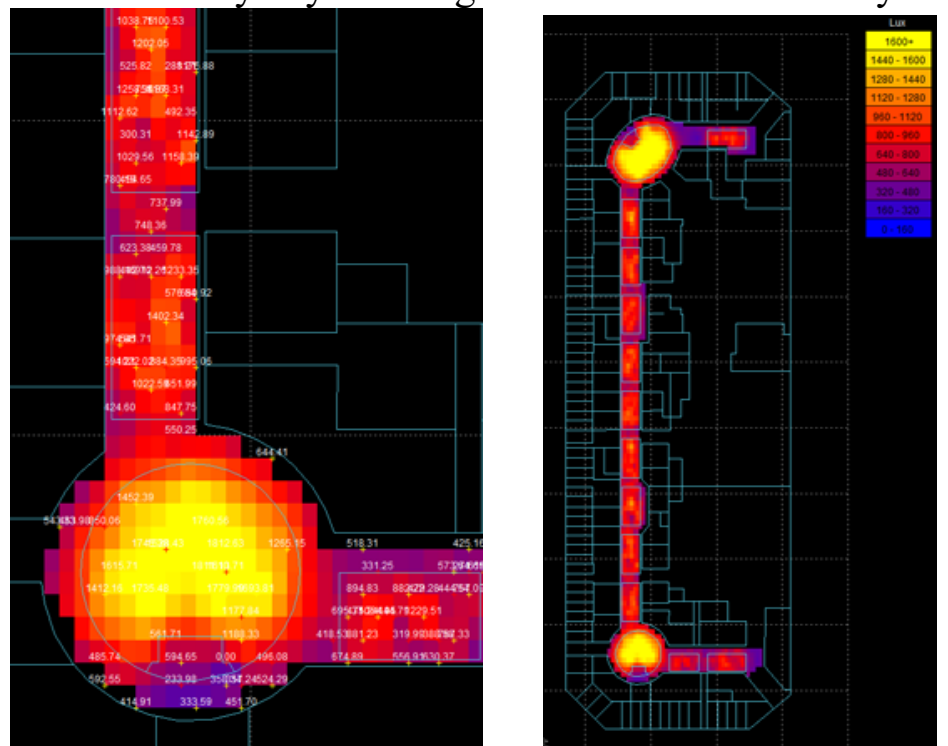

Figure 3 Overall simulation result and atrium peak value by Radiance

\section{Effect of skylight area on energy consumption and lighting effect of building}

Of which, the blue area is cold load and red area is hot cold, the load undertaken by cold engine in the whole year is $717800 \mathrm{kWh}$. The accumulated air conditioning energy consumption of pedestrian area unit square in the whole year is $119.63 \mathrm{kWh} / \mathrm{m}^{2}$.

In DEST, this paper respectively sets skylight square as $85 \%, 70 \%, 55 \%$ of current square, the air conditioning energy consumption table by simulation calculation in the whole year is indicated by 2.1: 
Table 2.1 Analysis table on cold load of indoor pedestrian mall area of different skylight area

\begin{tabular}{|c|c|c|}
\hline & $\begin{array}{c}\text { Accumulated air } \\
\text { conditioning load of } \\
\text { indoor pedestrian mall } \\
\text { in the whole year } \\
(\mathbf{k W h})\end{array}$ & $\begin{array}{c}\text { Accumulated air conditioning } \\
\text { load of indoor pedestrian mall } \\
\text { unit square in the whole year } \\
(\mathbf{k W h} / \mathbf{m})\end{array}$ \\
\hline $\begin{array}{c}\text { Original design } \\
\text { skylight }\end{array}$ & 71.78 & 119.63 \\
\hline $\begin{array}{c}\text { Skylight educed to } \\
\mathbf{8 5 \%}\end{array}$ & 70.01 & 116.68 \\
\hline $\begin{array}{c}\text { Skylight reduced to } \\
\mathbf{7 0 \%}\end{array}$ & 67.63 & 112.72 \\
\hline $\begin{array}{c}\text { Skylight reduced to } \\
\mathbf{5 5 \%}\end{array}$ & 65.08 & 108.46 \\
\hline
\end{tabular}

It can be seen that reduction in skylight square can decrease indoor radiation heat and heat transfer penetrates into skylight, so that it can reduce indoor air conditioning cold load in the whole year. This point will increase hot load of air conditioning in winter, but it only takes up a small part compared with reduced cold load, especially in Guangzhou, the hot load of building itself only takes up very small part of energy consumption, so the overall air conditioning load has been reduced.

However, because of reduction in skylight square, effect of indoor natural lighting also reduces, some time section only relies on illumination of natural lighting dose not need to open lighting in the past can no longer meets illumination requirement of indoor 300lx in the upscale mall, so it needs to make simulation by Radiance and calculate the standard area of indoor Pedestrian area of skylight area under 4 percentage, and then it can calculate change of lighting energy consumption.

Usually, the lighting energy consumption saved by natural lighting adopts the following formula to make calculation:

The average lighting power density of pedestrian area in one large shopping mall of Guangzhou at present is $14 \mathrm{~W} / \mathrm{m}^{2}$, the amounted hour number of completely opening in one day is $10.9 \mathrm{~h}$, the accumulated lighting energy consumption in the whole year is $334200 \mathrm{kWh}$, the accumulated lighting energy consumption of unit area in the whole year is $55.70 \mathrm{kWh} / \mathrm{m}^{2}$. In the Radiance simulation, it respectively makes simulation at middy 12 of $15^{\text {th }}$ in March, midday 12 of $15^{\text {th }}$ in June, midday $12^{\text {th }}$ of $15^{\text {th }}$ in September and midday 12 of $15^{\text {th }}$ in December, which respectively represents spring, summer, autumn and winter. It uses CIE cloudy day model to make simulation, which represents cloudy day and when it uses CIE sunny sky model to make simulation, which represents sunny day.

The simulation results are as follows:

Table 2.2 The standard area percentage of pedestrian area on the first floor (\%)

\begin{tabular}{|c|c|c|c|c|c|}
\hline \multicolumn{2}{|l|}{$x$} & $\begin{array}{l}\text { Current } \\
\text { skylight }\end{array}$ & $\begin{array}{c}\mathbf{8 5 \%} \\
\text { skylight }\end{array}$ & $70 \%$ skylight & $\begin{array}{c}55 \% \\
\text { skylight }\end{array}$ \\
\hline \multirow{2}{*}{ spring } & Sunny day & 95 & 92 & 88 & 82 \\
\hline & Cloudy day & 88 & 71 & 68 & 64 \\
\hline \multirow{2}{*}{$\underset{r}{\text { Summe }}$} & Sunny day & 95 & 95 & 90 & 87 \\
\hline & Cloudy day & 95 & 90 & 86 & 84 \\
\hline \multirow{2}{*}{ autumn } & Sunny day & 95 & 95 & 92 & 87 \\
\hline & Cloudy day & 95 & 89 & 87 & 81 \\
\hline \multirow{2}{*}{ winter } & Sunny day & 95 & 95 & 90 & 85 \\
\hline & Cloudy day & 93 & 88 & 81 & 75 \\
\hline
\end{tabular}


Table 2.3 The standard area percentage of pedestrian area of the second floor (\%)

\begin{tabular}{|c|c|c|c|c|c|}
\hline \multicolumn{2}{|l|}{3} & $\begin{array}{l}\text { Current } \\
\text { skylight }\end{array}$ & $\begin{array}{c}85 \% \\
\text { skylight }\end{array}$ & $70 \%$ skylight & $55 \%$ skylight \\
\hline \multirow{2}{*}{ spring } & Sunny day & 85 & 77 & 75 & 72 \\
\hline & Cloudy day & 71 & 65 & 62 & 60 \\
\hline \multirow{2}{*}{ Summer } & Sunny day & 85 & 80 & 77 & 75 \\
\hline & Cloudy day & 85 & 72 & 67 & 65 \\
\hline \multirow{2}{*}{ autumn } & Sunny day & 85 & 81 & 79 & 76 \\
\hline & Cloudy day & 85 & 74 & 72 & 66 \\
\hline \multirow{2}{*}{ winter } & Sunny day & 85 & 80 & 76 & 74 \\
\hline & Cloudy day & 76 & 71 & 66 & 63 \\
\hline
\end{tabular}

Table 2.4 The standard area percentage of pedestrian area of the third floor (\%)

\begin{tabular}{|c|c|c|c|c|c|}
\hline \multicolumn{2}{|c|}{} & $\begin{array}{c}\text { Current } \\
\text { skylight }\end{array}$ & $\mathbf{8 5 \%}$ skylight & $\mathbf{7 0 \%}$ skylight & $\mathbf{5 5 \%}$ skylight \\
\hline \multirow{2}{*}{ spring } & Sunny day & 90 & 90 & 90 & 84 \\
\cline { 2 - 6 } & Cloudy day & 90 & 84 & 84 & 77 \\
\hline \multirow{2}{*}{ Summer } & Sunny day & 90 & 90 & 90 & 85 \\
\cline { 2 - 6 } & Cloudy day & 90 & 88 & 87 & 79 \\
\hline \multirow{2}{*}{ autumn } & Sunny day & 90 & 90 & 90 & 84 \\
\cline { 2 - 6 } & Cloudy day & 90 & 89 & 86 & 87 \\
\hline \multirow{2}{*}{ winter } & Sunny day & 90 & 90 & 90 & 78 \\
\cline { 2 - 6 } & Cloudy day & 90 & 88 & 86 & 87 \\
\hline
\end{tabular}

Because 2 atriums and middle area in the first floor are all raised ceiling, so the pedestrian area in the second and third floor is composed of many annular regions, the area is very small. The area ratio of pedestrian area in the first, second and third floor is about $2: 1: 1$.

From the simulation result we can see the following:

The standard area percentage in the first floor decrease with skylight area, which presents linear decline trend

The standard area percentage on the second floor abruptly decreases in $100 \%$ skylight area and $85 \%$ skylight area, it also presents linear decline trend. This is because the center in the first floor is raise ceiling space, the pedestrian area on the second floor is annular region, of which some parts are right below the skylight, and the natural lighting is not affected by reduction of skylight area. While the other part is in the outer side of skylight, when skylight reduces, natural lighting will be shaded by structure on the third floor, which causes some areas can not achieve the standard.

The third floor is just below the skylight, incidence angle of natural light is very broad, so area can not achieve standard will increase when skylight area is reduced from $70 \%$ to $55 \%$.

From simulation result, we can calculate the completely opening time amounts to every day under different skylight area is as follows 
Table 2.5 The completely opening time every day amounts

\begin{tabular}{|c|c|c|c|c|}
\hline & $\begin{array}{c}\text { Original } \\
\text { skylight area }\end{array}$ & $\begin{array}{c}\mathbf{8 5 \%} \text { skylight } \\
\text { area }\end{array}$ & $\begin{array}{c}\mathbf{7 0 \%} \text { skylight } \\
\text { area }\end{array}$ & $\begin{array}{c}\mathbf{5 5 \%} \text { skylight } \\
\text { area }\end{array}$ \\
\hline $\begin{array}{c}\text { Completely } \\
\text { opening time }\end{array}$ & 10.9 & 11.07 & 11.19 & 11.37 \\
\hline (h) & & 1.07 & \\
\hline
\end{tabular}

According to lighting energy consumption saved by natural lighting and calculation formula it calculates lighting energy consumption and air conditioning energy consumption of pedestrian mall with different opening area, which is indicated by the following table:

Table 2.6 Analysis table on lighting energy consumption of indoor pedestrian mall with different skylight area

\begin{tabular}{|c|c|c|c|}
\hline & $\begin{array}{c}\text { Accumulated air } \\
\text { conditioning load } \\
\text { of indoor } \\
\text { pedestrian mall in } \\
\text { the whole year } \\
(\mathbf{1 0 0 0 0} \mathbf{k W h})\end{array}$ & $\begin{array}{c}\text { Accumulated lighting } \\
\text { load of indoor } \\
\text { pedestrian mall in } \\
\text { the whole year } \\
\text { (10000 kWh) }\end{array}$ & $\begin{array}{c}\text { Air } \\
\text { conditioning } \\
\text { +lighting } \\
\text { (10000 kWh) }\end{array}$ \\
\hline $\begin{array}{c}\text { Original design } \\
\text { skylight }\end{array}$ & 71.78 & 33.42 & 105.2 \\
\hline $\begin{array}{c}\text { Skylight reduced to } \\
\mathbf{8 5 \%}\end{array}$ & 70.01 & 33.94 & 103.95 \\
\hline $\begin{array}{c}\text { Skylight reduced to } \\
\mathbf{7 0 \%}\end{array}$ & 67.63 & 34.31 & 101.94 \\
\hline $\begin{array}{c}\text { Skylight reduced to } \\
\mathbf{5 5 \%}\end{array}$ & 65.08 & 34.87 & 99.95 \\
\hline
\end{tabular}

It can be seen that as for building, reduction in skylight area can decrease energy consumption in the pedestrian mall, when skylight is reduced to $55 \%$, it can reduce $5 \%$ energy consumption in the pedestrian mall.

Some simulation results calculated by Radiance are as follows:
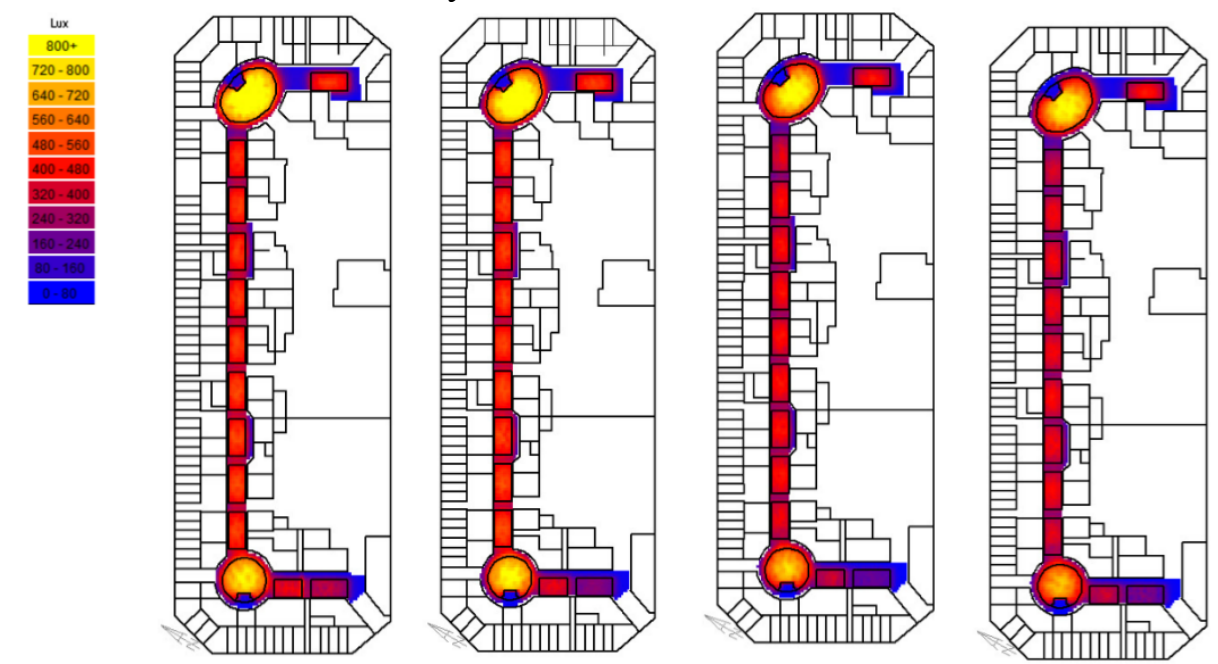

Figure 4 Illumination simulation result in summer of skylight of $100 \%, 85 \%, 70 \%$ and $55 \%$ on the first floor in summer

\section{Conclusion}

This paper uses and combines with DEST energy consumption simulation and lighting simulation of Radiance to make analysis on air conditioning energy consumption and lighting energy consumption of one large shopping mall in Guangzhou affected by different skylight areas, 
and it gets the following conclusion:

As for this building, reduction in skylight area cannot obviously increase the opening time of lights. Therefore, on condition of taking no consideration of indoor satisfaction, we can possibly reduce skylight area, so that reduce the overall energy consumption. When skylight area is reduced to $55 \%$ of current area, it can reduce the overall energy consumption of pedestrian area.

\section{Reference}

[1] Danny H. W..Li Ernest K..W. Tsang.An analysis of daylighting performance for office buildings in Hong Kong[J].Building and Environment.2008(43): 1446-1458

[2] Zhou Xuefan. High-rise office building natural lighting design based on energy conservation strategy research [D]. Master's degree in huazhong university of science and technology. 2010

[3] Athanassios Tzempelikos. The impact of shading design and control[J].Solar Energy.2007

[4] Danny H..W. Li..Daylight and energy implications for CIE standard skies[J].Energy Conversion and Management.2007(48): 745-755

[5] Paul Littlefair.Daylight Prediction In Atrium Buildings[J].Solar Energy.2002.73(2):105-109

[6] Christoph Reinhart.Annegret Fitz.Findings from a survey on the current use of daylight simulations in building design[J].Energy and Buildings.2006(38): 824-835

[7] Sharifah Fairuz Syed Fadzila.Sheau-Jiunn Sia.Sunlight control and daylight distribution analysis: the KOMTAR case study[J].Building and Environment.2004(39): 713-717

[8] A. Zain-Ahmed.K. Sopian. Z. Zainol 等.The availability of daylight from tropical skies-a case study of Malaysia[J].Renewable Energy.2002(25): 21-30

[9] hoi mang meet. Large space outside the top lighting sunshade thermal performance study [D]. Master degree theses of master of hebei university of technology. 2013

[10] yan, xiao-na xie, Song Fangting ycas. Building simulation technology and the introduction of DeST development [J]. Journal of hvac. (34) : 2004-56

[11] Liao Liang. DeST comparative analysis with other building environment simulation software [C]. Professional committee of the national hvac air conditioning simulation analysis of academic communication. 2004 